\title{
Corrigendum: Take a "Selfie": Examining How Leaders Emerge From Leader Self-Awareness, Self-Leadership, and Self-Efficacy
}

\author{
Eva M. Bracht ${ }^{1 *}$, Fong T. Keng-Highberger ${ }^{2}$, Bruce J. Avolio ${ }^{3}$ and Yiming Huang ${ }^{4}$ \\ ${ }^{1}$ Department of Social Psychology, Institute of Psychology, Goethe University, Frankfurt, Germany, ${ }^{2}$ Nanyang Business \\ School, Nanyang Technological University, Singapore, Singapore, ${ }^{3}$ Foster School of Business, University of Washington, \\ Seattle, WA, United States, ${ }^{4}$ School of Business, Nanjing University, Nanjing, China
}

Keywords: information processing theory, leadership emergence, leader self-awareness, leader self-efficacy, self-leadership, social cognitive theory

\section{A Corrigendum on}

OPEN ACCESS

Approved by:

Frontiers in Editorial Office, Frontiers Media SA, Switzerland

*Correspondence: Eva M. Bracht ebracht@psych.uni-frankfurt.de

Specialty section

This article was submitted to Organizational Psychology,

a section of the journal

Frontiers in Psychology

Received: 22 July 2021 Accepted: 28 July 2021 Published: 23 August 2021

Citation: Bracht EM, Keng-Highberger FT,

Avolio BJ and Huang Y (2021)

Corrigendum: Take a "Selfie": Examining How Leaders Emerge From

Leader Self-Awareness, Self-Leadership, and Self-Efficacy.

Front. Psychol. 12:745910.

doi: 10.3389/fpsyg.2021.745910
Take a "Selfie": Examining How Leaders Emerge From Leader Self-Awareness, Self-Leadership, and Self-Efficacy

by Bracht, E. M., Keng-Highberger, F. T., Avolio, B. J., and Huang, Y. (2021). Front. Psychol. 12:635085. doi: 10.3389/fpsyg.2021.635085

In the original article, there was an error. The Ethics Statement incorrectly stated that "Ethical review and approval was not required for the study on human participants in accordance with the local legislation and institutional requirements. The patients/participants provided their written informed consent to participate in this study."

A correction has been made to the Ethics Statement. The corrected statement is shown below.

The studies involving human participants were reviewed and approved by Nanyang Technological University (NTU) Institutional Review Board (IRB-2020-04-004). The participants provided their written informed consent to participate in this study.

The authors apologize for this error and state that this does not change the scientific conclusions of the article in any way. The original article has been updated.

Publisher's Note: All claims expressed in this article are solely those of the authors and do not necessarily represent those of their affiliated organizations, or those of the publisher, the editors and the reviewers. Any product that may be evaluated in this article, or claim that may be made by its manufacturer, is not guaranteed or endorsed by the publisher.

Copyright $\odot 2021$ Bracht, Keng-Highberger, Avolio and Huang. This is an open-access article distributed under the terms of the Creative Commons Attribution License (CC BY). The use, distribution or reproduction in other forums is permitted, provided the original author(s) and the copyright owner(s) are credited and that the original publication in this journal is cited, in accordance with accepted academic practice. No use, distribution or reproduction is permitted which does not comply with these terms. 